\title{
On a modification in the pycnometer
}

\section{Eilhard Wiedemann}

To cite this article: Eilhard Wiedemann (1883) On a modification in the pycnometer, Philosophical Magazine Series 5, 15:95, 369-371, DOI: 10.1080/14786448308627366

To link to this article: http://dx.doi.org/10.1080/14786448308627366

曲 Published online: 28 Apr 2009.

Submit your article to this journal $\pi$

Џll Article views: 2

Q View related articles $₫$ 
increase of momentum in a given time : in other words, forces will be proportional to $\mathrm{m} \frac{\mathrm{dv}}{\mathrm{dt}}$. From this it is but a step (though it may be a false step) to say that the force $i$ s the rate of increase of momentum, and nothing else, and respectfully to demand that we shall reconstruct the whole of Mechanics in accordance with that definition. Mr. Close takes an illustration from the rate of mortality ; and I will follow him. Disease causes death, and the strength of different diseases, or of the same disease at different times and places, may fairly be measured by the rate of mortality (say the number of deaths per 1000 per diem) which they induce. Mr. Close, if consistent with himself, would therefore define disease as being the rate of mortality-that and nothing else; and would require all our medical literature to be rewritten, because its language does not square with the new definition.

I think it is time that the advocates of the new view should themselves bring out a book, showing that the ordinary laws and propositions of Mechanics can be worked out on their principles in a way intelligible to the ordinary student. Prof. Tait, in a recent communication to the Royal Society of Edinburgh, made a sort of commencement of such a work : I should be glad to hear of any ordinary student who has derived much comfort and clearness of thought from a study of the result. For an attempt of the kind I refer to, but on the opposite lines, I may perhaps be allowed to point to a recent work of my own, entitled 'The Student's Mechanics : an Introduction to the Study of Force and Motion.'

May I be allowed to conclude with one word in reply to Mr. von Tunzelmann's letter on the Conservation of Energy: it is simply to point out that a periodic function is not the same thing as a constant.

Walter R. Browne.

\section{ON A MODIFICATION IN THE PYCNOMETER.} BY EILHARD WIEDEMANN.

Since determinations of the specific gravity of solids for the purpose of discovering relations between it and their chemical constitution are now more and more frequently made, the improvement of the pycnometer communicated in what follows may not be without interest. By means of it results as exact can be obtained with powders as when larger bodies are employed.

$A s$ is well known, in the former method the pycnometer is first weighed empty, then filled with water, then with the substance in question, and finally with water and the substance. If the weights in these cases are $\mathrm{P}, \Pi, p$ and $\pi$, the specific gravity of the substance is

$$
s=\frac{p-\mathbf{P}}{[\mathbf{\Pi}+(p-\mathrm{P})]-\pi} .
$$

But air is always contained between the particles of the solid, 
and can only be expelled by well boiling, and not always even then. Hence to substances that are decomposed or fused by heating, this method, in the form hitherto used, is not applicable, or at any rate gives extremely inexact results. Also with substances that are easily held in suspension by water or remain on its surface, as finely divided sulphate of barium, the results obtained are inexact, as these substances do not after the boiling sink again to the bottom, and consequently are in part squeezed out with the surplus water on the insertion of the stopper.

For the filling of the pycnometer I have used a method already described by me*, in which the disturbing effect of the air is completely excluded. A is the pycnometer, into which the ground stopper $a$ fits ; this is passed through by a glass tube, which is bent back at $b$ and ends at $c$ inside a slip, of which the outer part is attached to the piece $d g$ consisting of narrow glass tubes ; $f$ and $e$ are cocks, $h$ a small funnel, and $g$ the inner part of a slip whose outer part is connected with a good mercury air-pump such as should now be found in every laboratory.

First the pycnometer and the slightly greased stopper are now weighed by themselves; in doing this it is best to suspend the latter on its hook $b$ by means of a wire. They are then to be connected with the part $d g$; close $e$, its cavity having been previously filled with a drop of water; open $f$, and exhaust. to vacuum; then let the previoasly well boiled water flow in from $h$;

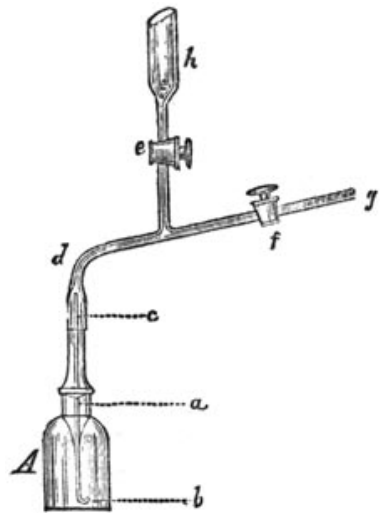
disconnect the pycnometer at $c$, wipe off the grease from it and weigh it. Then dry it, introduce the powder, and repeat the same procedure. The tube is bent back at $b$ in order that the powder may not be too much stirred up when the liquid flows in. If the pycnometer, $A$, selected is a small one and we first exhaust completely all the space between the cock $f$ and the pump, a three or four times repeated action of the pump suffices to make the space in A a vacuum. In the time required for this, even salts containing water, of which the vapour does not possess at all too high a tension, as, for example, the double sulphates of zinc and magnesium with potassium and ammonium, lose only so small a quantity of their water of crystallization that for them sufficiently accurate results are obtained.

As illustrations of the precision of the method, in the following are communicated two series of measurements, made on powdered glass and precipitated sulphate of barium. They were carried out

* Wied. Ann. xvii. p. 561 (1882). 
with great care by $\mathbf{R}$. Schulze. For each single measurement from about a half to three quarters of an hour was required.

I. Glass Powder.

\begin{tabular}{|c|c|c|c|c|c|}
\hline $\mathrm{P}$ & $\mathrm{I}$ & \multicolumn{1}{|c|}{$p$} & \multicolumn{1}{|c|}{$\pi$} & Temp. & \multicolumn{1}{|c|}{$s$} \\
\hline $9 \cdot 2554$ & $19 \cdot 4095$ & $\mathbf{1 4} \cdot 3788$ & $22 \cdot 4468$ & $15 \cdot 7$ & $2 \cdot 4559$ \\
$9 \cdot 2554$ & $19 \cdot 4095$ & $10 \cdot 5368$ & $20 \cdot 1689$ & $16 \cdot 4$ & $2 \cdot 4547$ \\
$9 \cdot 2554$ & $19 \cdot 4095$ & $13 \cdot 608$ & $21 \cdot 9894$ & $15 \cdot 1$ & $2 \cdot 4553$ \\
$9 \cdot 2554$ & $19 \cdot 4095$ & $13 \cdot 271$ & $21 \cdot 7895$ & $16 \cdot 4$ & $2 \cdot 4551$ \\
\hline
\end{tabular}

II. Sulphate of Barium.

\begin{tabular}{|c|c|c|c|c|c|}
\hline $\mathbf{P}$ & II & $p$ & $\pi$ & Temp. & $s$ \\
\hline 92554 & $19 \cdot 4095$ & $10 \cdot 5962$ & $20 \cdot 445$ & $14^{\circ} \cdot 9$ & 43958 \\
\hline $9 \cdot 2554$ & $19 \cdot 4095$ & $11 \cdot 7652$ & $21 \cdot 3484$ & $14 \cdot 9$ & 4.3962 \\
\hline $9 \cdot 2554$ & $19 \cdot 4095$ & $14 \cdot 333$ & $23 \cdot 3323$ & $14: 5$ & $4 \cdot 3969$ \\
\hline $9 \cdot 2554$ & $19 \cdot 4095$ & $13 \cdot 0445$ & $22 \cdot 3368$ & 14.5 & $4 \cdot 3967$ \\
\hline
\end{tabular}

The specific gravities differ from one another by not quite a unit in the third decimal place, a result which may be regarded as extremely satisfactory.

If a greater number of determinations of specific gravity have to be effected, it would be advisable to employ several pycnometers, attached to different arms connected with the air-pump and exhausted simultaneously. This would effect a pretty considerable saving of time.-Wiedemann's Annalen, 1882, xvii. pp. 983-985.

\section{ON THE UPPER LIMIT OF THE PERCEPTIBILITY OF SOUNDS. BY E. PAUCHON.}

I have the honour of communicating to the Academy the results of some researches on the determination of the upper limit of perceptibility of sounds, a portion of which were made in conjunction with M. L. Bertrand.

I proposed to ascertain if, as several physicists have alleged (although they have not brought forward any experiment proving their assertion), this limit varies, for one and the same ear, with the intensity of the sound. For this purpose I employ a powerful Caignard-Latour siren, modified in some of its parts, and set in action by a jet of steam. Various arrangements, described in a 